\title{
Effect of Marine Sponge Sigmadocia fibulata (Schmidt) and Suberites carnosus (Johnston) on Histpathological Examination of Liver, Kidney, Heart, Lung and Brain Tissues of Female Sprague Dawley Rats
}

\author{
Bhadekar N. S*, Zodape G.V
}

Department of Zoology S.S. \& L.S. Patkar College of Arts and Science \& V.P. Varde College of Commerce \& Economics, S.V. Road, Goregaon West, Mumbai- 400 062, India

DOI: $10.36348 /$ sjmps.2020.v06i03.005

| Received: 15.03.2020 | Accepted: 22.03.2020 | Published: 27.03.2020

*Corresponding author: Bhadekar N. S

\section{Abstract}

The $\mathrm{LD}_{50}$ values of sponge Sigmadocia fibulata and Suberites carnosus were evaluated as $\mathrm{O}=$ Survival and $\mathrm{X}=\mathrm{Death}$. For both the samples we found that the $\mathrm{LD}_{50}$ is greater than $2000 \mathrm{mg} / \mathrm{kg}$. In histopathological examinations of liver the crude extract Sigmadocia fibulata showed congested vasculature and focal minimal degenerative changes in hepatic parenchyma with cellular swelling and vacuolar changes of hepatocytes were noted, where as in normal control and rats treated with crude extract of Suberites carnosus, no metabolic or pathological lesions in liver tissue sections were observed. In kidney tissue rats treated with crude extract of Suberites carnosus showed focal congestion of vessels in renal parenchyma. The focal areas showed cellular swelling in renal tubules with presence of granular cytoplasmic changes in the epithelium of tubules showing absence of inflammatory changes in the section; where as in normal control and rats treated with Sigmadocia fibulata no metabolic or pathological lesions in kidney tissue sections were observed. In the histological examinations of heart, lung, and brain tissues no observable changes were noted in normal control and experimental rats, treated with crude extract of Sigmadocia fibulata and Suberites carnosus.

Keywords: Sponge, $\mathrm{LD}_{50}$, histopathology, crude extract, Sprague dawley rats.

Copyright @ 2020: This is an open-access article distributed under the terms of the Creative Commons Attribution license which permits unrestricted use, distribution, and reproduction in any medium for non-commercial use (NonCommercial, or CC-BY-NC) provided the original author and source are credited.

\section{INTRODUCTION}

India has total length of the coastline is around $8014 \mathrm{Km}$ which includes coastline of two groups of oceanic islands namely Andaman and Nicobar and Lakshadweep. India possess a vast Exclusive Economic Zone of 20,13,410 Sq. Km and territorial waters of $1,55889 \mathrm{Sq} \mathrm{Km}$. The Indian coast has a variety of sensitive ecosystem like lagoons, sand dunes, coral reefs, mangroves, sea grass beds and wetlands. Arabian Sea enriches the Mumbai with a shore line of $100 \mathrm{Km}$, coastal areas in and around Mumbai are biologically most productive areas supporting a wealth of marine resources. Mumbai $\left(18^{\circ} 53^{\prime}\right.$ to $19^{\circ} 16^{\prime} \mathrm{N}$ latitude and $72^{\circ} 48^{\prime}$ to $72^{\circ} 53^{\prime}$ E longitude) is an island situated on the west coast of the Indian peninsula on the Arabian Sea. Mumbai was built on cluster of seven islets. Now it forms a mass of islands, measuring three miles in width. This area is northern end to rock at Colaba and its southern end at the Northern Konkan coast. A deep natural harbour is located to the east and at the south part off Colaba Point there is the Prong's Reef reefs area, which is unprotected in spring low tide. The rocks of these reef areas lengthen up to the Nariman Point. The island is linked at its northern part with the larger Salsette Island by two causeways, at Mahim one and the other at Sion [1].

Sponges offer a rich source of unique and diverse natural products. Marine sponges are potential sources of unique bioactive metabolites and many of these compounds are valuable for medicinal uses. Sponges produce a wide array of secondary metabolites ranging from derivatives of amino acids and nucleosides to macrolides, porphyrins, terpenoids, aliphatic cyclic peroxides and sterols [2]. Many of these compounds have potent pharmacological activities, including anti-tumor, fungal, viral, and bacterial properties, some of which are currently in preclinical or clinical trials [3]. However, natural products were also found to play important biological and ecological roles for the producing organisms such as defense against predators, competition for space, prevention of fouling, roles in reproduction, and antimicrobial activity. Several antibiotics have been isolated, such as plakortin [4] and manoalide [5] from marine Sponges. Over 60\% 
of potentially useful bioactive compounds discovered so far from living organisms have been obtained from marine fauna, $70 \%$ of which comes from sponges [6]. There are approximately 15,000 different species of sponges throughout the globe. To date, more than 5,000 different compounds have been isolated from about 500 species of sponges [7]. Out of which 150 of which occur in freshwater, but only about 17 present commercial values for traditional use, including the cosmetic industry. A total of 486 sponge species have been found in Indian waters [8]. The sponge class Demospongiae is known for producing the largest number and diversity of secondary metabolites isolated from marine invertebrates [9]. There is a worldwide interest in marine natural products as one of the few de novo sources of drug discovery [10]. However, the bioactive potential of compounds from Indian sponges has been little studied. Therefore the present study comprises an initial effort to assess the bioactivity of secondary metabolites from the marine subtidal sponges Sigmadocia fibulata (Schmidt) and Suberites carnosus (Johnston) to explore the bioactive compounds from Sigmadocia fibulata (Schmidt) and Suberites carnosus
(Johnston). In the present study, we have selected the sponges Sigmadocia fibulata (Schmidt) and Suberites carnosus (Johnston) from Mumbai coasts and its extract was investigated for histological study.

\section{Materials and Methods}

Collection of Samples

The sponges Sigmadocia fibulata (Schmidt) and Suberites carnosus (Johnston) were collected during low tides from West Coast of Mumbai. Animals were taken alive to the laboratory in seawater washed under sea water and then with distilled water and sun dried.

\section{Identification of Sponges}

Preliminary identification was done by studying the shape and size of the spicules and by refereeing the relevant literature. The confirmation of identification was done by Dr. P. A. Thomas, Principal Scientist, Central Marine Fisheries Research Institute (CMFRI), Thiruvananthapuram, Kerala
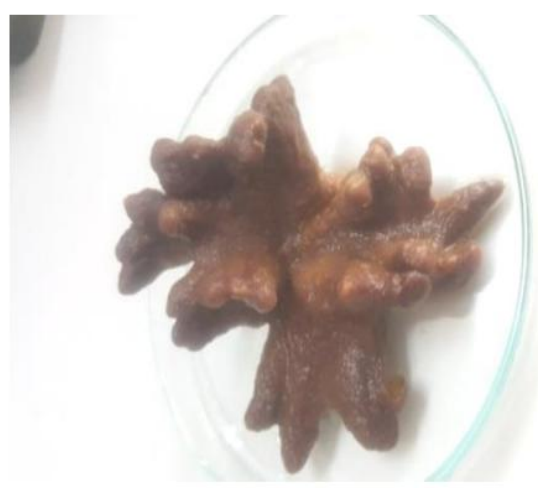

Sigmadocia fibulata (Schmidt, 1862)

Suberites carnosus (Johnston, 1842)

\section{Tylostyles}

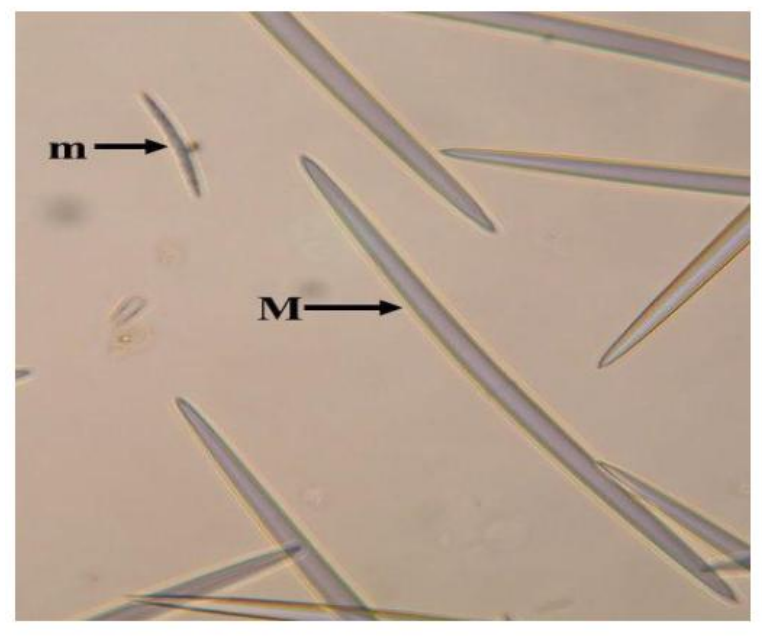

M- Megascleres

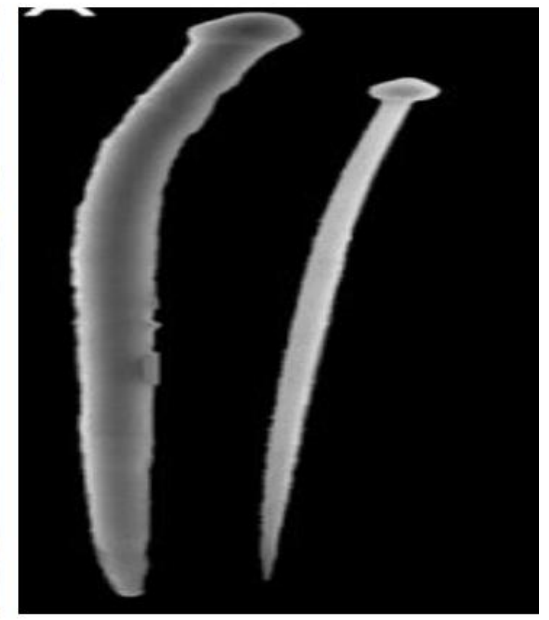

$\mathrm{m}$ - Microscleres 


\section{Preparation of Sponge Extracts}

Crude extract was obtained following the method of [11] with some modifications. To 10 gram of sponge samples, $10 \mathrm{ml}$ of methanol was added and kept standing for $24 \mathrm{hrs}$. Solvent were then removed, by squeezing sponge samples, and filtered through Whatman filter paper No.1. The remaining solvent was

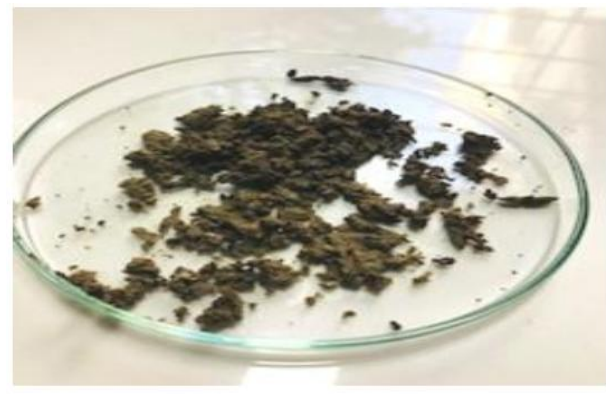

Sigmadocia fibulata (Schmidt, 1862)

\section{Ethical Approval}

Ethical approval is received by Maharashtra State Biodiversity Board, Nagpur for collection of sponges for research purpose. The voucher specimens of Sigmadocia fibulata and Suberites carnosus, was evaporated at low pressure using Rotary Vacuum Evaporator at $45^{\circ} \mathrm{C}$. The resultant compound was subjected to Millipore filter system and finally dried in a vacuum desiccator and stored at $4{ }^{\circ} \mathrm{C}$ in a refrigerator till further use.

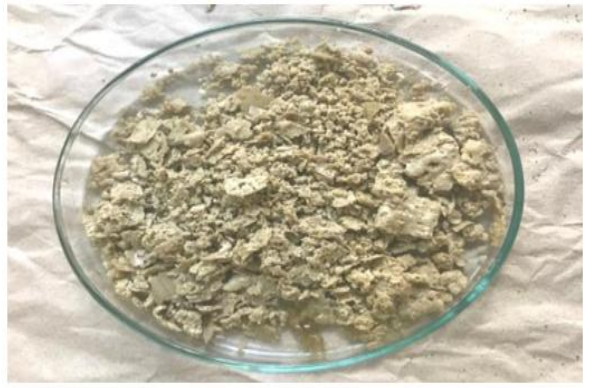

Suberites carnosus (Johnston, 1842)

deposited at the repository centre at NIO Goa, India, as per the directions by Maharashtra State Biodiversity Board. The Voucher numbers of the said specimens are 1-NIO1006/18 (Sigmadocia fibulata) and 2NIO1007/18 (Suberites carnosus).

\section{Evaluation of LD50 value of marine sponges:}

Table-1: Showing Test System and Management of female Sprague Dawley Rats

\begin{tabular}{|l|c|l|}
\hline 1. Species & $:$ & Rat \\
\hline 2. Strain & $:$ & Sprague Dawley Rats \\
\hline 3. Source & $:$ & APT Testing and Research Pvt. Ltd., Pune \\
\hline 4. Sex & $:$ & Females \\
\hline 5. Body weight range & $:$ & $150-180$ gm \\
\hline 6. Identification & $:$ & $\begin{array}{l}\text { By unique identification number marked by writing on cage tag and by } \\
\text { corresponding colour body markings. }\end{array}$ \\
\hline 7. No. of animals & $:$ & 30 \\
\hline 8.Acclimatization & $:$ & $\begin{array}{l}\text { The rats were housed in their cages for five days prior to start of dosing in the } \\
\text { experimental room after veterinary examination. }\end{array}$ \\
\hline $\begin{array}{l}\text { 9. Environmental } \\
\text { conditions }\end{array}$ & $:$ & $\begin{array}{l}\text { Room temperature maintained between } 22+3^{0} \text { C, relative humidity 50-60 } \% \text { and } \\
\text { illumination cycle set to 12 hours light and 12 hours dark. }\end{array}$ \\
\hline 10. Accommodation & $:$ & $\begin{array}{l}\text { Three rats were housed in each polypropylene cages with stainless steel grill top, } \\
\text { facilities for food and water bottle, and bedding of clean paddy husk. }\end{array}$ \\
\hline 11. Diet & $:$ & Pelleted feed supplied by Supplier. \\
\hline 12. Water & $:$ & $\begin{array}{l}\text { Potable water passed through 'Aquaguard' water filter was provided ad libitum } \\
\text { in plastic bottles with stainless steel sipper tubes. }\end{array}$ \\
\hline
\end{tabular}

\section{Procurement of animals}

Thirty (30) female Sprague dawley rats (average weight 150-180 g) were used for the experiment. They were purchased and procured from the National Toxicological Centre, APT Testing \& Research Pvt. Ltd. (ATR) Pune. The experimental study was approved by Ethical committee at APT Research Foundation, Pune prior to the experimentation (IAEC NO. APTRF/ RP 57/1819 dated 01 February 2019). The animals were acclimatized, maintained and housed in
APT laboratory for five days. Room temperature maintained between $22 \pm 3^{0} \mathrm{C}$, relative humidity 50-60\% and illumination cycle set to 12 hours light and 12 hours dark cycle was also maintained by feeding the rats with commercial rat pallets and Potable water passed through 'Aquaguard' water filter was provided ad libitum in plastic bottles with stainless steel sipper tubes. 


\section{Administration of Test Article}

The test article at the concentration of 2000 $\mathrm{mg} / \mathrm{kg}$ was administered to each rat by a single oral gavage. The animals were dosed using a stainless steel intubation needle fitted onto a suitably graduated syringe. The dosage volume administered to individual rat was adjusted according to its most recently recorded body weight. Animal weights were determined weekly along with food consumption. Animals were randomly divided into two groups containing 5 animals in each group. The present experiment was undertaken to evaluate the LD50 value of marine sponges Sigmadocia fibulata (Schmidt) and Suberites carnosus (Johnston) of west coast of Mumbai. The study was performed as per OECD guideline 425 .

\section{Histopathological Examination}

The liver, Kidney, Heart, Lung, and Brain tissues were dissected out and fixed in $10 \%$ formalin, dehydrated in gradual ethanol (50-100\%), cleared in xylene, and embedded in paraffin. Five micron thick sections were prepared and then stained with hematoxylin and eosin $(\mathrm{H}-\mathrm{E})$ dye for photomicroscopic observation, including cell necrosis, fatty degenerative changes, hyaline regeneration, ballooning degeneration as proposed by [12], and histological structure of liver, Kidney, Heart, Lung, and Brain tissue were examined under the Biological digital microscope Motic B1 Series.

\section{RESUlTS AND DiSCUSSION}

Table-2: Showing the changes in body weights (gm) of female Sprague dawley rats for the period of 14 days

\begin{tabular}{|l|l|l|l|l|l|}
\hline Group & Sex & Marking & 0 Day & 7 Day & 14 Day \\
\hline \multirow{4}{*}{$\begin{array}{l}\text { Sprague dawley rats treated with } \\
\text { Suberites carnosus }\end{array}$} & $\mathrm{F}$ & $\mathrm{RH}$ & 116.0 & 131.0 & 149.0 \\
\cline { 2 - 6 } & $\mathrm{F}$ & $\mathrm{RF}$ & 114.0 & 126.5 & 134.5 \\
\cline { 2 - 6 } & $\mathrm{F}$ & $\mathrm{RLS}$ & 113.0 & 136.0 & 153.5 \\
\cline { 2 - 6 } & $\mathrm{F}$ & $\mathrm{H}-\mathrm{RH}$ & 119.0 & 131.0 & 145.0 \\
\cline { 2 - 6 } & $\mathrm{F}$ & $\mathrm{H}-\mathrm{RLS}$ & 116.0 & 129.0 & 144.0 \\
\hline \multirow{4}{*}{$\begin{array}{l}\text { Sprague dawley rats treated with } \\
\text { Sigmadocia fibulata }\end{array}$} & $\mathrm{F}$ & $\mathrm{LLS}$ & 115.0 & 129.0 & 142.0 \\
\cline { 2 - 6 } & $\mathrm{F}$ & $\mathrm{LF}$ & 120.0 & 139.0 & 156.0 \\
\cline { 2 - 6 } & $\mathrm{F}$ & $\mathrm{LH}$ & 119.0 & 133.0 & 149.0 \\
\cline { 2 - 6 } & $\mathrm{F}$ & $\mathrm{H}-\mathrm{LH}$ & 112.0 & 124.0 & 138.0 \\
\cline { 2 - 6 } & $\mathrm{F}$ & $\mathrm{H}-\mathrm{LLS}$ & 114.0 & 127.0 & 139.0 \\
\hline
\end{tabular}

Fig 1-5 Showing effect of Sigmadocia fibulata (Schmidt) and Suberites carnosus (Johnston) extract on histopathological examination of liver, kidney, heart, lung, and brain tissues.

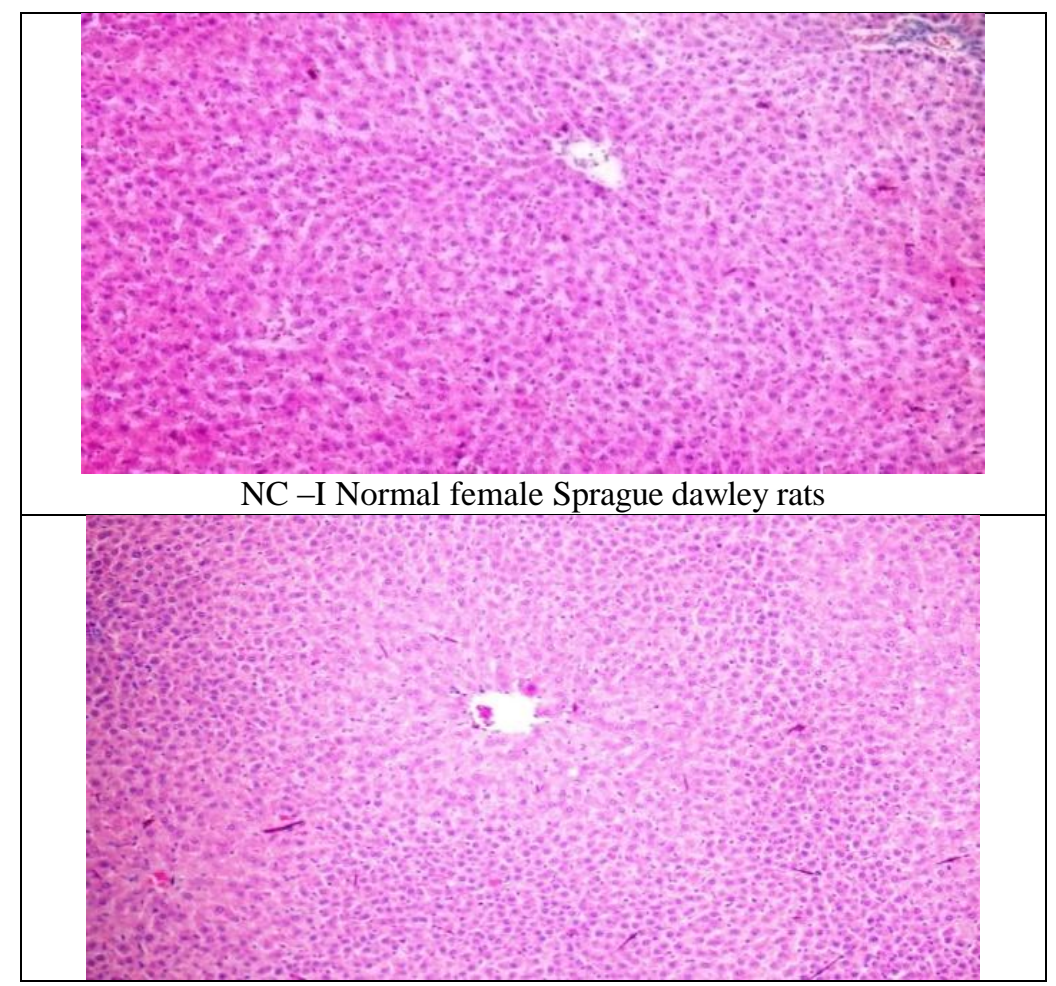




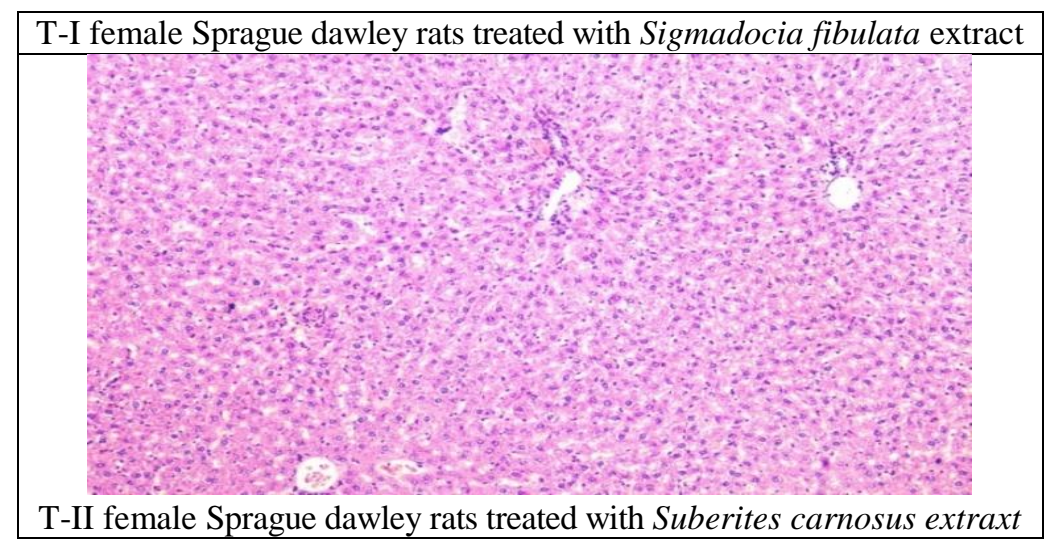

Fig-1: Showing Histopathological observations of liver tissue of female Sprague dawley rats

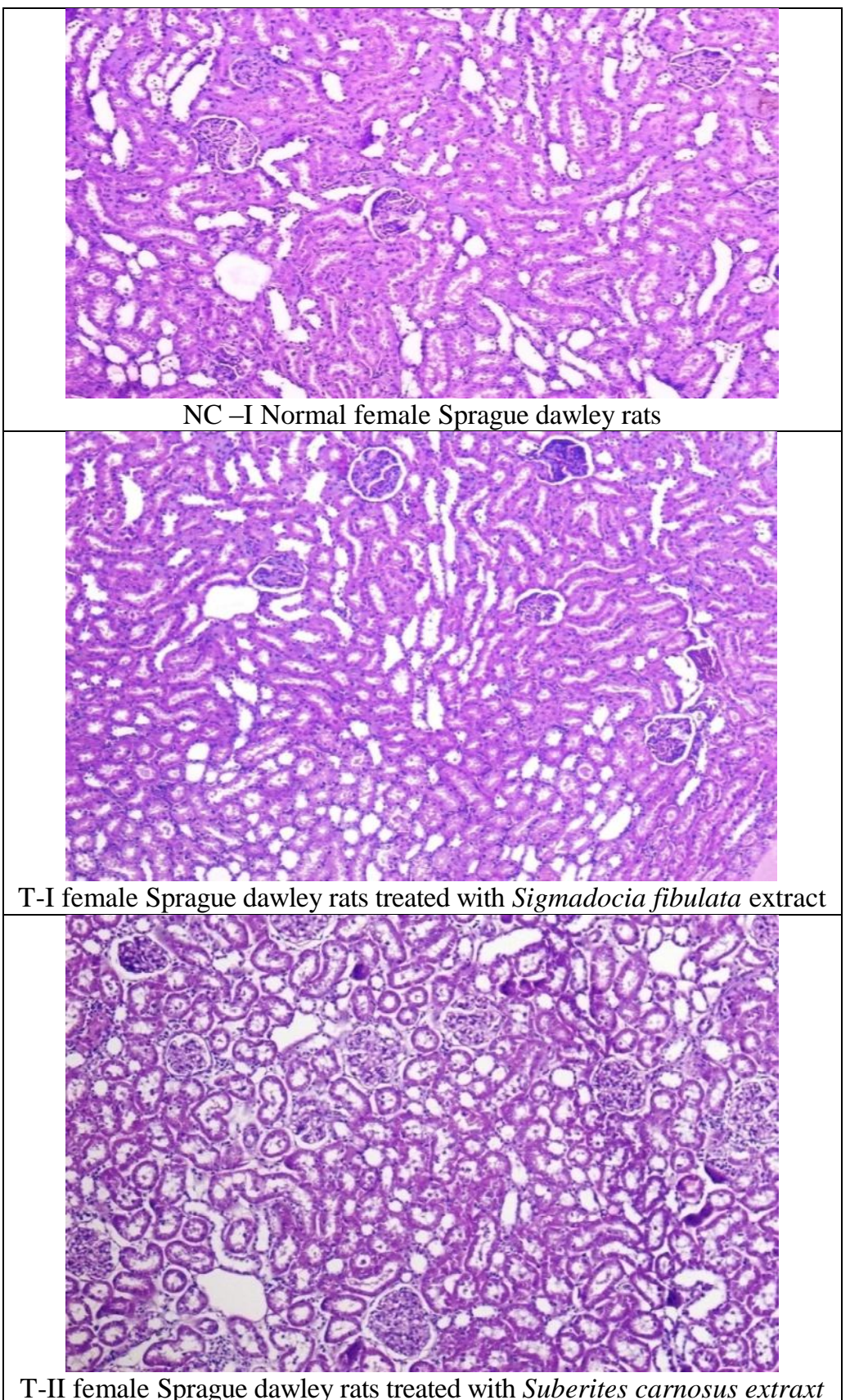

T-II female Sprague dawley rats treated with Suberites carnosus extraxt

Fig-2: Showing Histopathological observations of kidney tissue of female Sprague dawley rats 
Bhadekar N. S \& Zodape G.V; Saudi J Med Pharm Sci, March., 2020; 6(3): 281-290

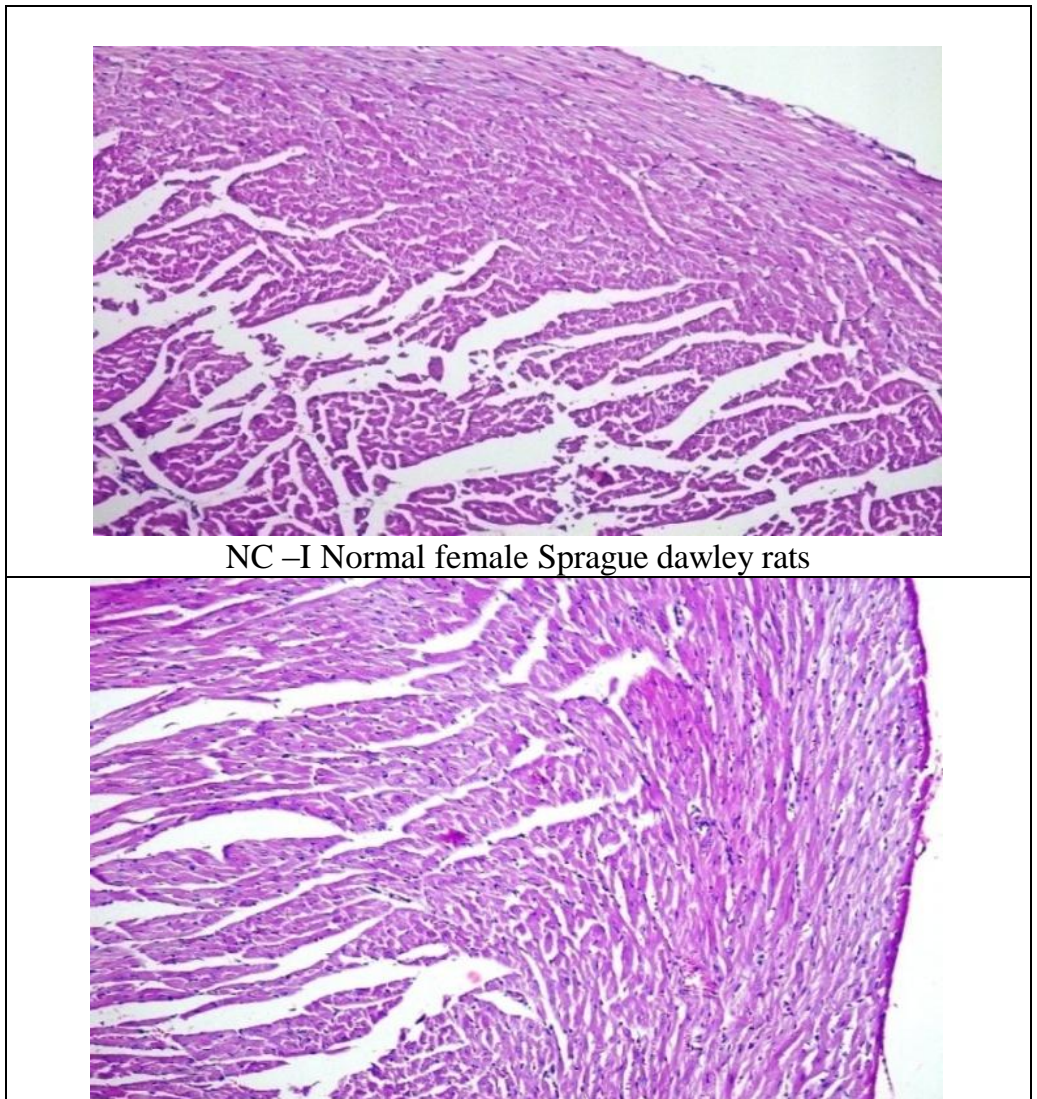

T-I female Sprague dawley rats treated with Sigmadocia fibulata extract

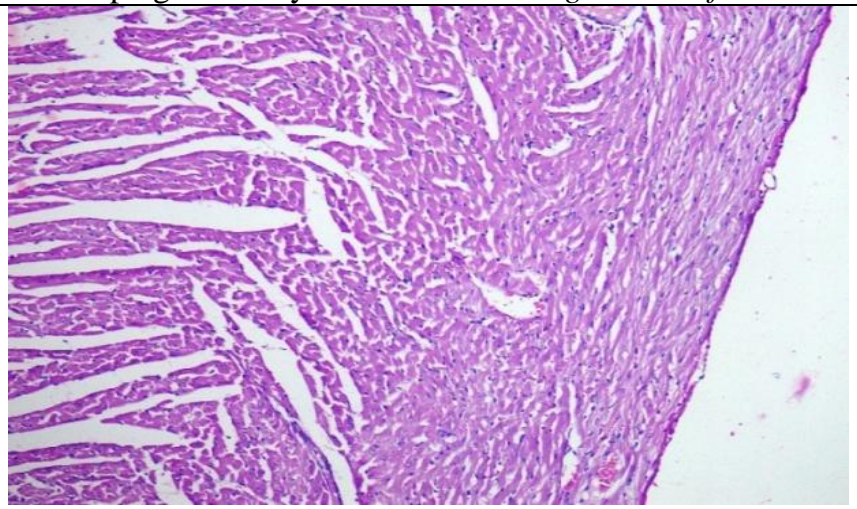

T-II female Sprague dawley rats treated with Suberites carnosus extraxt Fig-3: Showing Histopathological observations of heart tissue of female Sprague dawley rats

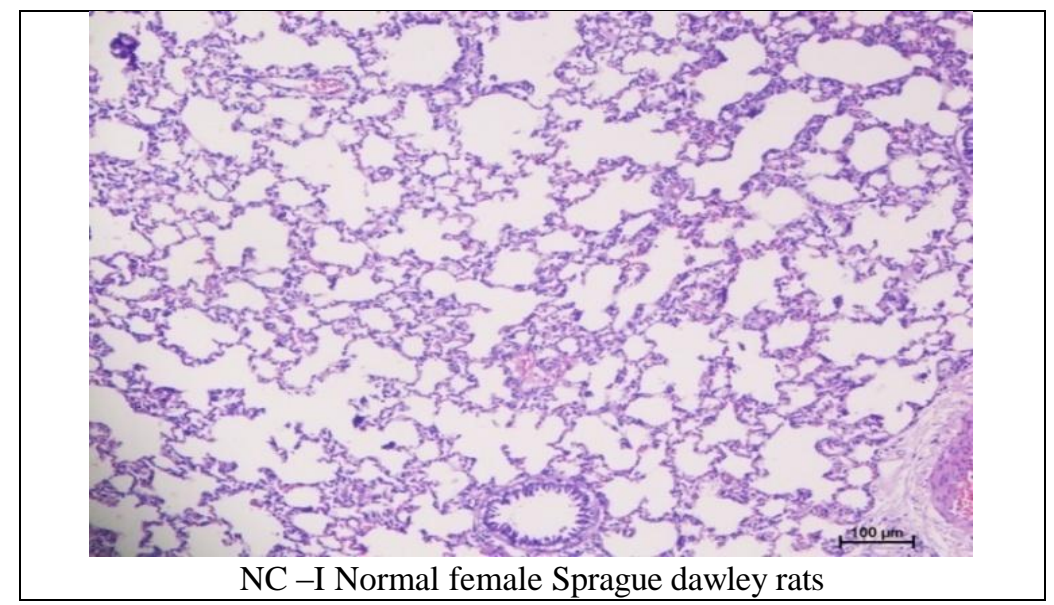


Bhadekar N. S \& Zodape G.V; Saudi J Med Pharm Sci, March., 2020; 6(3): 281-290

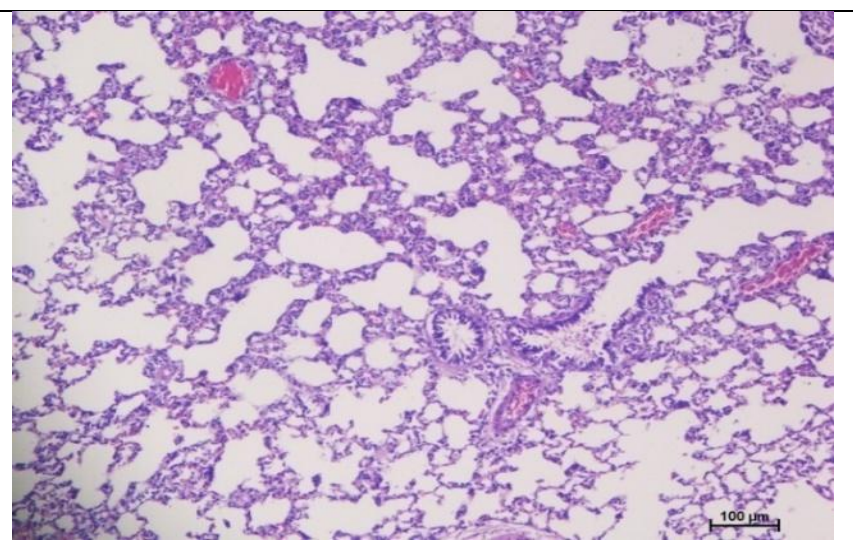

T-I female Sprague dawley rats treated with Sigmadocia fibulata extract

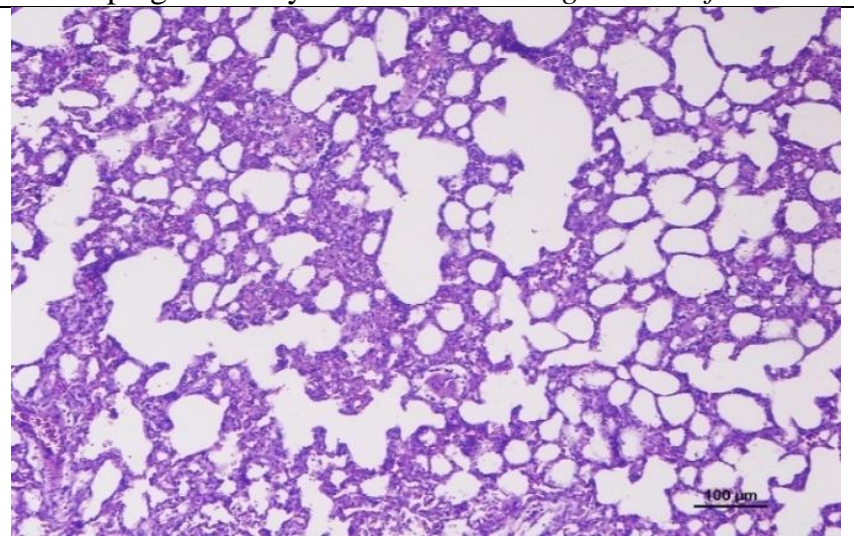

T-II female Sprague dawley rats treated with Suberites carnosus extraxt Fig-4: Showing Histopathological observations of lung tissue of female Sprague dawley rats

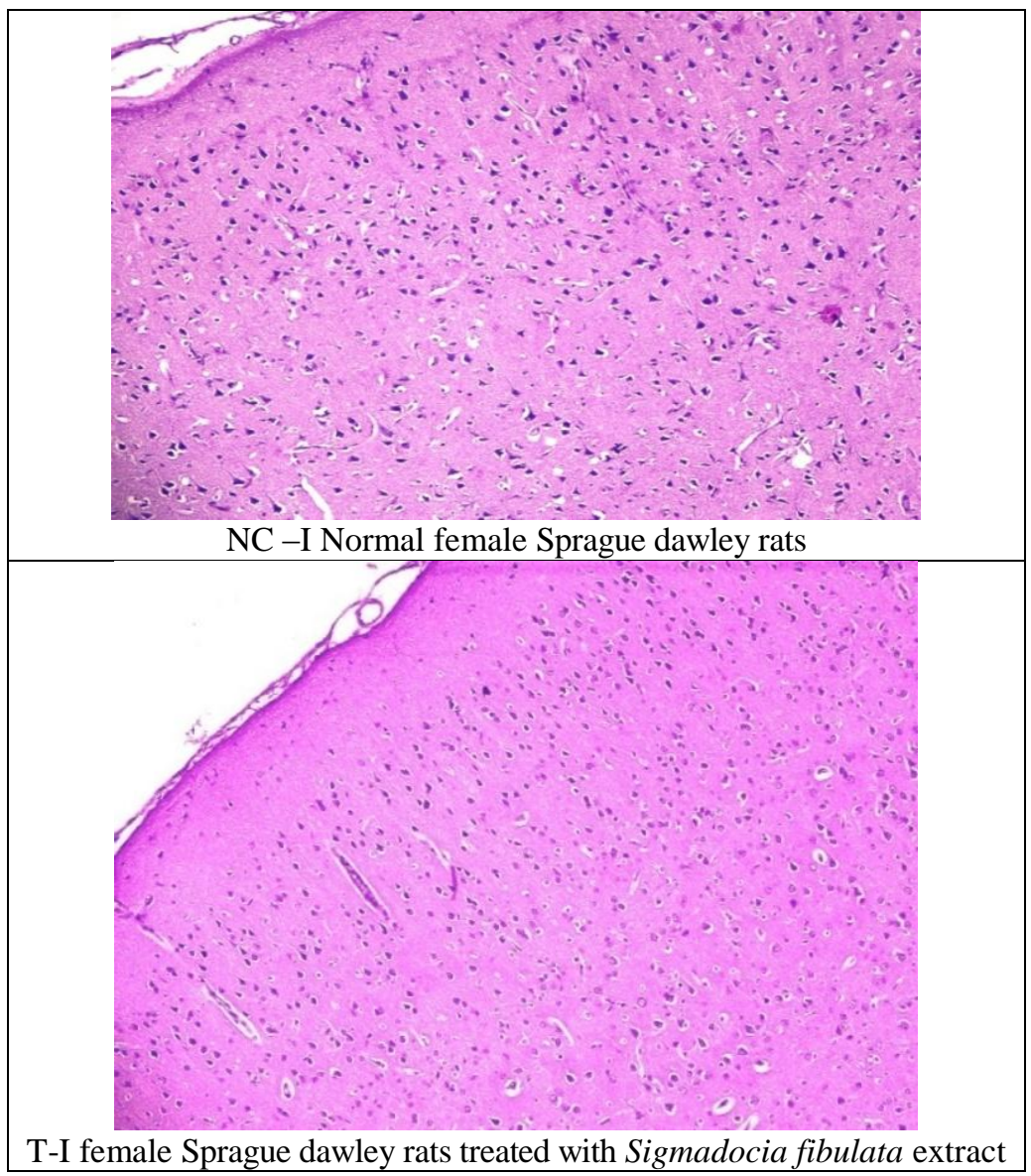




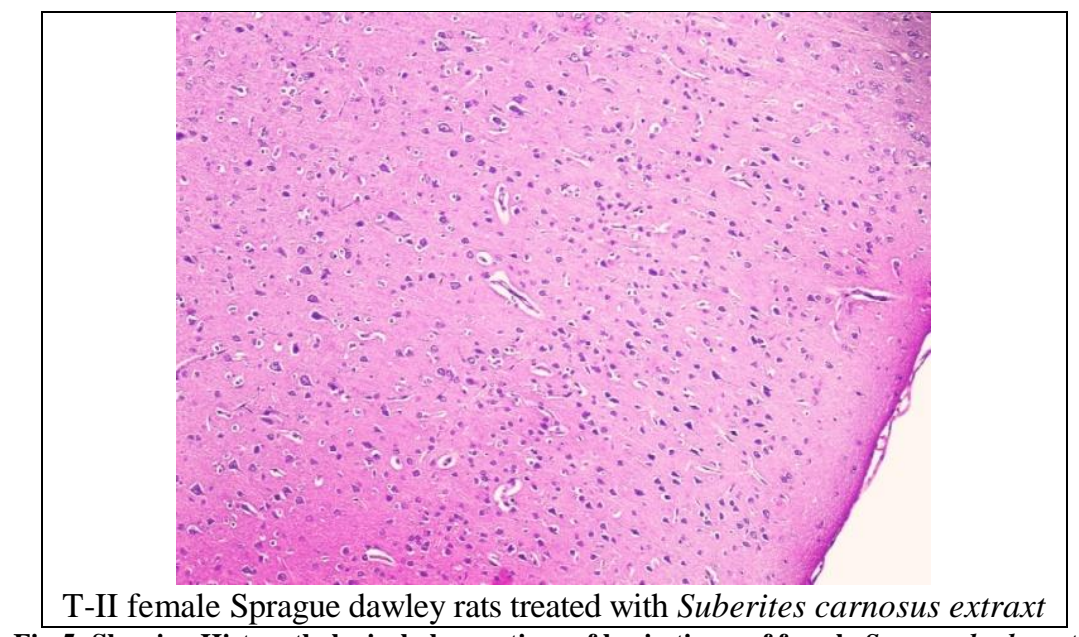

Fig-5: Showing Histopathological observations of brain tissue of female Sprague dawley rats.

Table-1 Showing test system and management of female Sprague dawley rats treated with crude extract of Sigmadocia fibulata and Suberites carnosus for the period of 14 days. Animals were kept on fasting prior to dosing. The limit test is performed in 5 animals. A test dose of $2000 \mathrm{mg} / \mathrm{kg}$ was used for the study. The test substance is administered in a single dose by gavage using a stomach tube (oral feeding needle). Animals were dosed one at a time. As the animal survived, additional four animals were dosed sequentially so that a total of five animals would be tested. All animals were observed for 14 days after dosing. The results were evaluated as $\mathrm{O}=$ Survival and $\mathrm{X}=$ Death. For both samples Sigmadocia fibulata and Suberites carnosus the LD50 is greater than 2000 $\mathrm{mg} / \mathrm{kg}$.

Table-2 showing the changes in body weights (gm) of female Sprague dawley rats treated with crude extract of Sigmadocia fibulata and Suberites carnosus for the period of 14 days.

Body weight was measured weekly during the study period of 14 days wherein, no statistically significant changes were observed in the body weights of test group animals as compared to normal control on respective days. Similarly, food consumption was also measured weekly wherein no statistically significant changes were observed in food consumption of test group animals as compared to normal control.

Fig-1 Showing Histopathological observations of liver tissue of female Sprague dawley rats. NC-I Normal female Sprague dawley rats, the liver tissue showed normal hepatic parenchyma with normal histomorphology of hepatocytes with an intact cell borders and nucleus. There is an absence of any degenerative or inflammatory changes in the liver parenchyma and an absence of any metabolic or pathological lesions in liver tissue sections. In case of T-I female Sprague dawley rats treated with crude extract Sigmadocia fibulata showed congested vasculature and focal minimal degenerative changes in hepatic parenchyma with cellular swelling and vacuolar changes of hepatocytes were noted. Where as in case of T-II female Sprague dawley rats treated with crude extract of Suberites carnosus showed normal hepatic parenchyma with normal histomorphology of hepatocytes with an intact cell borders and nucleus. There is an absence of any degenerative or inflammatory changes in the liver parenchyma and an absence of any metabolic or pathological lesions in liver tissue sections.

Fig-2 Showing Histopathological observations of kidney tissue of female Sprague dawley rats. NC-I Normal female Sprague dawley rats, kidney tissue showed normal histomorphology of glomeruli and renal tubules with intact cellular features and intact nucleus in tubules. In T-I female Sprague dawley rats treated with crude extract of Sigmadocia fibulata showed normal histomorphology of glomeruli and renal tubules with intact cellular features and intact nucleus in tubules. Where as in case of T-II female Sprague dawley rats treated with crude extract of Suberites carnosus showed focal congestion of vessels in renal parenchyma. The focal areas showed cellular swelling in renal tubules with presence of granular cytoplasmic changes in the epithelium of tubules showing absence of inflammatory changes in the section.

Fig-3 Showing Histopathological observations of heart tissue of female Sprague dawley rats. NC-I Normal female Sprague dawley rats, showed normal histomorphology of cardiac muscles with intact nucleus and intact length of cardio-myofibers in all the sections of heart (endocardium, myocardium and pericardium). The absence of any pathological changes in the heart and blood vessels were not seen. In T-I and T-II female Sprague dawley rats treated with crude extract of Sigmadocia fibulata and Suberites carnosus respectively, no observable changes were noted and heart showed normal histomorphology of cardiac muscles with intact nucleus and intact length of cardio- 
myofibers in all the sections of heart (endocardium, myocardium and pericardium). The absence of any pathological changes in the heart and blood vessels were not seen.

Fig-4 Showing Histopathological observations of lung tissue of female Sprague dawley rats. NC-I Normal female Sprague dawley rats, normal histological features of lung tissue comprised of primary and secondary bronchi with intact epithelium. It also showed normal cellular details of alveoli of the lung tissue and focal congested blood vascular tissue, with an absence of any pathological changes in the lung tissue section. In T-I and T-II female Sprague dawley rats treated with crude extract of Sigmadocia fibulata and Suberites carnosus, no observable changes were noted in lung tissues. It showed normal histological features of lung tissue comprised of primary and secondary bronchi with intact epithelium. It also showed normal cellular details of alveoli of the lung tissue and focal congested blood vascular tissue, with an absence of any pathological changes in the lung tissue section.

Fig-5 Showing Histopathological observations of brain tissue of female Sprague dawley rats. NC-I Normal female Sprague dawley rats, showed normal cellular features of brain tissue comprised of neurons and supportive matrix. It has also been observed that the histological features of neurons with intact nucleus showing normal size. There is an absence of any pathological or inflammatory lesions in the brain tissue. In T-I and T-II female Sprague dawley rats treated with crude extract of Sigmadocia fibulata and Suberites carnosus, also showed normal cellular features of brain tissue comprised of neurons and supportive matrix. It has also been observed that the histological features of neurons with intact nucleus showing normal size. There is an absence of any pathological or inflammatory lesions in the brain tissue.

In our study the $\mathrm{LD}_{50}$ values of sponge Sigmadocia fibulata and Suberites carnosus were evaluated as $\mathrm{O}=$ Survival and $\mathrm{X}=$ Death. For both the samples we found that the $\mathrm{LD}_{50}$ is greater than 2000 $\mathrm{mg} / \mathrm{kg}$. In histopathological examinations we found that in liver histopathological investigations, in case of rats treated with crude extract Sigmadocia fibulata showed congested vasculature and focal minimal degenerative changes in hepatic parenchyma with cellular swelling and vacuolar changes of hepatocytes were noted, where as in normal control rats and rats treated with crude extract of Suberites carnosus, no metabolic or pathological lesions in liver tissue sections were observed. In kidney tissue rats treated with crude extract of Suberites carnosus showed focal congestion of vessels in renal parenchyma. The focal areas showed cellular swelling in renal tubules with presence of granular cytoplasmic changes in the epithelium of tubules showing absence of inflammatory changes in the section, where as in normal control rats and rats treated with crude extract of Sigmadocia fibulata no metabolic or pathological lesions in kidney tissue sections were observed. In the histological examinations of heart, lung, and brain tissues no observable changes were noted in normal control and experimental rats, treated with crude extract of Sigmadocia fibulata and Suberites carnosus.

\section{CONCLUSION}

The bioactive compounds extracted from marine organisms plays inhibitory role in different diseases. Its inhibitory mechanism is depending on its mode of action. In addition to that, limited tests make the substances to get their exact mode of action and their origin. Most of the bioactive substances showed their potential of inhibiting certain enzymes for their physiological actions. Whereas certain bioactive compounds acts as a mediator for certain intracellular and intercellular activities as messengers and get directly involved in the pathogenesis of different diseases. Marine sponges produce large amount of bioactive compounds in association with other symbiotic species for their defense mechanisms. These bioactive compounds play an important role to treat many kinds of infections like antimicrobial agents, antibiotic, antiinflammatory compounds, immunosuppressive compounds and can also affect pathogenesis of many diseases. Few sponge derived compounds are used as drugs are available in the market for various diseases. Potency of these drugs based on their fact based efficacy and their side effects. Herein above study we found bioactivity against liver and kidney tissues and no activity was noted against heart, lung, and brain tissues.

\section{ACKNOWLEDGEMENT}

Authors would like to thank to, Director, APT Testing \& Research Pvt. Ltd. (ATR) Pune, for providing the female Sprague dawley rats used for the experiment and approved by Ethical committee at APT Research Foundation, Pune prior to the experimentation.

Conflict of interest: There is no conflict of interest.

\section{REFERENCES}

1. Jaiswar, A. K. (1999). Intertidal biodiversity with reference to mollusks in and around Mumbai (Doctoral dissertation, $\mathrm{PhD}$ thesis, University of Mumbai).

2. El-masry, A. H., Fahmy, H. H., \& Ali Abdelwahed, S. H. (2000). Synthesis and antimicrobial activity of some new benzimidazole derivatives. Molecules, 5(12), 1429-1438.

3. Newman, D. J., \& Cragg, G. M. (2004). Marine natural products and related compounds in clinical 
and advanced preclinical trials. Journal of natural products, 67(8), 1216-1238.

4. Higgs DJ, Faulkner. Plakortin, an antibiotic from Plakortis halichondrioides. J Org Chem. 1978, 43: 3454-3457.

5. DE, S., de Silva, E. D., \& PJ, S. (1980). Manoalide, an antibiotic sesterterpenoid from the marine sponge Luffariella variabilis (Polejaeff). Tetrahedron Letters, 21:1611-1614.

6. Abas, H. H., Zulfigar, Y., \& Chan, K. L. (1999). Cytotoxicity and drug metabolism screening of several marine sponges from Pulau Pasir, Kedah and Pulau Aur, Johor. Asean Review of Biodiversity and Environmental Conservation,(ARBEC), 1-5.

7. Rifai, S., Fassouane, A., El-Abbouyi, A., Wardani, A., Kijjoa, A., \& Van Soest, R. (2005). Screening of antimicrobial activity of marine sponge extracts. Journal de Mycologie Médicale, 15(1), 33-38.
8. Thomas, P. A. (1998). Porifera. In: Alfred, J. R.B., Das, A. K., Sanyal, A. K. editors. Faunal diversity in India. Calcutta: ENVIS Central Zoological Survey of India; 28-36.

9. Newbold, R. W., Jensen, P. R., Fenical, W., \& Pawlik, J. R. (1999). Antimicrobial activity of Caribbean sponge extracts. Aquatic microbial ecology, 19(3), 279-284.

10. McConnell, O. J., Longley, R. E., \& Koehn, F. E. (1994). The discovery of marine natural products with therapeutic potential. Biotechnology (Reading, Mass. ), 26, 109-174.

11. Braekman, J. C., Daloze, D., Stoller, C., \& Van Soest, R. W. (1992). Chemotaxonomy of Agelas (Porifera: Demospongiae). Biochemical systematics and ecology, 20(5), 417-431.

12. Davidson, C. S. (1979). Guidelines for detection ofhepatotoxicity due to drugs and chemicals.NIH publication, U.S. Department of Health and Education and Welfare NIH U.S.A. 